about the connexions of the limbic system from the thorough study of carefully selected human pathological material. Andersen and Eccles discussed physiological mechanisms underlying the 10/second rhythmical activity of the ventrobasal thalamus in the cat while Creutzfeldt, using the same animal, described relationships between E.E.G. waves and intracellular cortical activity. Madame Albe-Fessard and Jasper both presented exciting studies of single unit activity in thalamic nuclei of unanaesthetized patients undergoing stereotaxic surgery. Such neurophysiological tours de force, in addition to being useful to the surgeon for intrathalamic localization, provide a wealth of new information such as that suggesting the control of Parkinsonian tremor by populations of rhythmically firing cells in ventral thalamic nuclei.

This volume is a most interesting and impressive summary of current research and would have been even more useful as a reference had an index been appended.

\section{R. R. YOUNG}

CEREBRovascular DISEASE. Proceedings of the Association for Research in Nervous and Mental Disease. December 1961. Edited by C. H. Millikan. (Pp. x + 428; 90 figures, 112 tables. $£ 84 s$.) Baltimore: The Williams and Wilkins Company. 1966.

The most notable feature of this book is the length of time elapsing between presentation of papers and publication; a report of current research problems appearing after an interval of five years will surely find its way at once to the shelves reserved for medical antiquities. This would be a greater tragedy if the papers had been of outstanding interest or importance in the first place, but cerebrovascular disease had been the subject of so many published symposia at that time that many of the chapters now have a secondhand look even before the pages are cut. Among the honourable exceptions to this judgment are, however, the excellent reviews by Kety and by Lassen in the field of cerebral blood flow and by Groch, McDevitt, and Wright on the natural history of cerebrovascular disease. The final results of the well conducted cooperative study on longterm anticoagulants are presented briefly and lucidly by Fisher. The paper by Margolis on hypertensive intracerebral haemorrhage is notable not only for the presentation of his pathological studies on microaneurysms but for his stimulating ideas on the role of tension in vascular walls (as distinct from transmural pressure gradient). The chapters dealing with advances in treatment have inevitably suffered most from the delay in publication; it is salutary to read the uncritical enthusiasm for hyperbaric oxygen in view of the limitations which have now become apparent. A final absurdity is a report spanning 25 pages on the beneficial effects of fibrinolytic agents in occlusive cerebrovascular disease with a small footnote added subsequently to say that this form of treatment is now contraindicated.

COMPARATIVE AND CELlULAR PATHOPHYSIOLOGY OF EPILEPSY. Proceedings of a symposium held in Liblice, Prague, 20-24 September, 1965. Edited by Z. Servit.
(Pp. 375 ; illustrated. £9.) Amsterdam: Excerpta Medical Foundation. 1966.

This book is concerned with the basic physiology of epilepsy. In the first section the epileptic discharge at cellular level is considered. The second part is concerned with the epileptic reaction of the whole brain, as shown particularly in the electro-encephalogram, and with methods of evoking and altering these reactions. The third section considers some interesting problems in the structures concerned in propagation of seizure activity. Finally the audiogenic seizure in rodents is examined as a paradigm of epilepsy. The final result is a volume of considerable interest to the physiologist and, less directly, to the clinical neurologist dealing with epilepsy. Contributions vary in their readability and the calibre of the work reported, but all add something to our knowledge of the important pathophysiological background of epilepsy.

$$
\text { C. W. M. WHITTY }
$$

STUDIES IN MULTIPLE SCLEROSIS: Further Explorations on the Geographic Distribution of Multiple Sclerosis. Report of the Third Conference of the Commission on Geographic Neurology, Epidemiology, and Statistics of the World Federation of Neurology. Copenhagen, 7-8 September, 1963. Edited by Kay Hyllested and L. T. Kurland. (Pp. 176; illustrated. D.Kr. 35.) Copenhagen: Munksgaard. 1966.

The principal purpose of a symposium such as fathered this volume is to bring together workers sharing a common interest to facilitate an exchange of ideas and data. If it is judged desirable to communicate the proceedings to a wider public, one may ask that publication should occur while the news is still fresh-not after three years, as is the case here. Although almost all the papers in this anthology have already been published elsewhere, those interested in multiple sclerosis may find it convenient to have them all in a single volume. Discussion by the other contributors of some of the papers is also included, and raises some points of interest.

SCOLIOSIs By R. Roaf. (Pp. xi + 147; illustrated. 37s. 6d.)

Edinburgh: E. \& S. Livingstone Ltd. 1966.

This, as might be expected, is basically an orthopaedic text giving an account of the anatomy and mechanics of the vertebral column and of the cause of the derangements which lead to scoliosis.

The neurological complications are briefly mentioned and the conservative and operative treatment is fully described. The text is profusely and well illustrated with clinical photographs and radiographs.

THE MEMORY SYSTEM OF THE BRAIN BY J. Z. Young. (Pp. viii +128 ; 32 figures. 28s.) Oxford University Press. 1966.

The octopus presents an excellent model for the study of learning and memory in a simple form. The animal learns responses rapidly and learning can be readily reversed. It also has two sets of segregated neural structures which can be identified as serving visual and 
tactile memory and can be differentially injured. Moreover it commonly uses only one eye at a time so that visual training can be done exclusively in a monocular field. Professor Young and his co-workers have made full uses of these opportunities, as this book testifies.

In transferring the information gained to the human organism-which is not of course Professor Young's concern - the meaning of words may prove a stumbling block. To the clinician memory means the voluntary recall of past experience usually with some element of correct temporal orientation. It implies not only objective behaviour but also an element of subjective 'consciousness'. Professor Young, however, defines memory in more precise but more limited terms as 'the unit within which a record is stored'. The record is itself 'a representation within the memory'. This clear definition of terms is valuable and a safeguard, particularly when applying the findings to human memory. However, the anthropomorphic occasionally intrudes. The octopus's response in one situation is 'slow and cautious'. Slow is factual enough, but cautious seems to carry man-made implications. Nevertheless the computer approach which Professor Young uses to memory and other brain mechanisms can be a profitable mode of thought: and the concept of the brain as the computer of homeostasis for the organism will be recognized as useful as much by biologists of the human as of other animals.

This book is much concerned with the information code of the brain and in this context it considers especially neurones and their inter-connexions. The organization of dendritic fields is for instance examined as a possible anatomical basis for aspects of perception. Such a mechanism poses difficulties over 'generalization', an important aspect of learning and memory in higher mammals. Professor Young's solution is to reexamine the process of generalization and to suggest that it does not exist in a true sense: and that 'what we call by that name may be the result only of the great variety of experiences that active learning homeostats such as ourselves acquire over the years'. He seems less willing to accept chemical change as a basis for learning. 'We shall not understand (neural memory) by thinking of its chemistry alone, any more than we should learn how information is stored in a book by studying the chemistry of ink.' But neurones have nuclei and if chemistry includes the structure of D.N.A. the analogy with printer's ink is hardly valid.

This book contains valuable ideas and new and profitable ways of considering cerebral function. It also includes some distressing obscurity of thought or perhaps of expression. It should be widely read. It will both irritate and stimulate its readers.

$$
\text { C. W. M. WHITTY }
$$

ASPECTS OF LEARNING AND MEMORY Edited by D. Richter. (Pp. $x+182$; illustrated. 35s.) London: Heinemann. 1966.

Dr. Richter has rendered a service in bringing together these informed and informative papers about a complex, rapidly advancing subject. In a brief introductory note he draws attention to the diverse meanings attached to the two key words in the title, and very reasonably indicates that this slender book can deal with only limited aspects. The amount of ground covered is nevertheless considerable, and a number of the essays not only provide a survey of existing information but put forward theoretical proposals and hypotheses. This is particularly true of the characteristically far-sighted and luminous chapter by the late Sir John Gaddum. The majority of the papers are concerned with human beings, viewed from the standpoint of the neurologist, the psychologist, or the neuropathologist. However, in a lengthy final chapter Dr. Steele Russell digests the findings of some three hundred papers on the experimental study of learning and memory in animals.

DER SENSITIVE BEZIEHUNGSWAHN By E. Kretschmer. (Pp. V + 236; illustrated. DM 36.) Berlin: SpringerVerlag. 1966.

Among Kretschmer's original contributions to psychiatry, the little monograph on delusions of self-reference occurring in morbidly sensitive persons had a considerable influence in Germany from the time of its publication in 1918. But in English-speaking countries it had little impact. The reason usually given is that in it Kretschmer claimed too much and explained too little; but it is more likely that its intractable designation was responsible for the neglect it suffered: 'sensitive delusions of reference', the customary translation, is clumsy as well as incorrect.

The concept deserves a better fate. It is clear from this fourth edition, to which Professor Kretschmer's son has added an illuminating chapter on the history and scientific standing of the reaction type, that Kretschmer was introducing, concurrently with Birnbaum, the notion of multiple causation and dynamic relations whereby clinical structure could be analysed and utilized, without recourse to Freudian metapsychology. It was the same approach, broadly, as Adolf Mayer propounded in the U.S.A.

CLOSING THE GAP BETWEEN MEDICINE AND PSYCHIATRY By

W. Dorfman. (Pp. xvii + 209. \$8.50.) Springfield,

Illinois: Charles C. Thomas. 1966.

This well-intentioned statement of a blameless superficial attitude towards psychosomatic disorder would be more welcome if it were more discriminating and better written. Mixed metaphors abound-'Freud's findings not only removed the iron curtain that opened the door to the unconscious, but are at the very roots of the doctorpatient relationship'-and the meaning is sometimes impenetrable, e.g., "disease is not an abstract concept; it only occurs in individuals whose body and mind inevitably and unalterably remain well attached and completely integrated'. The literature cited is rather elementary, and many of the most solid and valuable papers are overlooked.

REIFUNG UND FORMUNG VON PERSÖNLICHKEITEN By M. Tramer. (Pp. 402; 5 figures; 1 table. DM 39.) Erlenbach-Zurich: Eugen Rentsch.

Professor Tramer, who was best known for his contributions to the psychiatry of childhood, had also a profound interest in the development of personality. $\mathrm{He}$ 